\title{
Melatonin as potential candidate to prevent the toxicity induced by chemical warfare agents
}

\author{
René Pita · José Marco-Contelles · Eva Ramos • \\ Javier del Pino $\cdot$ Alejandro Romero
}

Received: 18 July 2013 / Accepted: 29 July 2013 / Published online: 8 August 2013

(C) Springer-Verlag Berlin Heidelberg 2013

Chemical Warfare Agents (CWAs) are substances that can kill, injure or incapacitate people because of its pathophysiological effects. Many CWAs are able to generate free radicals and derived reactants, excitotoxicity and inflammatory processes; as consequence, they can produce neurological symptoms and damage in different organs.

Nowadays, total immediate decontamination after CWAs exposure is difficult to achieve, and there are no completely effective antidotes or treatments against these agents. In this complex scenario, we think that a broadspectrum multipotent molecule, such as melatonin, would be an interesting antidote and its use could provide a good strategy to counteract CWAs-induced injury.

Melatonin ( $N$-acetyl-5-methoxytryptamine), a versatile and pleiotropic molecule that modulates and controls oxidative stress by several mechanisms (Hengstler and Bolt 2007), is a well-known antioxidant and free radical scavenger (Tan et al. 1993; Reiter et al. 2001). Melatonin is also involved in several and important functions such as vasomotor control and adrenal function, possesses antiexcitatory actions, regulates immune function and energy metabolism, including anti-inflammatory properties (Hardeland et al. 2011). Melatonin is highly lipophilic and consequently

\section{R. Pita}

Chemical Defence Department, CBRN Defence School, Army Engineer School, Hoyo de Manzanares, 28240 Madrid, Spain

J. Marco-Contelles

Medicinal Chemistry Laboratory, Institute of General Organic

Chemistry, CSIC, Juan de la Cierva, 3, 28006 Madrid, Spain

E. Ramos · J. d. Pino $\cdot$ A. Romero $(\bowtie)$

Department of Toxicology and Pharmacology, Faculty of

Veterinary Medicine, Complutense University of Madrid,

Avda. Puerta de Hierro s/n, 28040 Madrid, Spain

e-mail:manarome@ucm.es crosses easily cell membranes, including blood brain barrier (Costa et al. 1995), reaching all subcellular compartments and allowing it to be administered either orally or intravenously. Taking into account melatonin's low toxicity and that patients treated with high doses of melatonin do not experience any harmful side effects (Seabra et al. 2000), its potential spectrum for improving medical treatment against CWAs seems to be wide.

The toxic effects of organophosphates (OPs) compounds such as the nerve agents are not limited to acetylcholinesterase inhibition. Oxidative stress is a major mechanism in the pathophysiology of several toxins and diseases. In both acute and chronic OPs toxicity, changes in antioxidant enzymes occur, and lipid peroxidation increases in many organs, especially in the brain. Moreover, an important neuro-inflammation process occurs after OPs exposure (Collombet 2011). Recent insights and new therapeutic perspectives about melatonin's anti-inflammatory properties and molecular aspects have been recently reviewed (Mauriz et al. 2012). However, it would be important to determine if the neuroprotective efficacy of melatonin against OPs could be effective as prophylactic and/or as post-exposure treatment, because some drugs exert higher protective activity when given under one set of conditions versus the other.

Oxidative stress is a key element in the pathogenesis of blister agent toxicity. Some studies have suggested that oxidative stress due to reactive oxygen species (ROS) play an important role in the toxic mechanism of action of mustard gas action (Jafari 2007). However, the powerful nitrosating agent $\mathrm{ONOO}^{\circ}$ is involved in the initial detrimental effects of all mustards (Korkmaz et al. 2006). Nowadays, both melatonin and its metabolites have important advantages when compared to "classical antioxidants" including iNOS inhibition and $\mathrm{ONOO}^{\circ}$ scavenging properties against mustard's induced acute toxicity (Sadir et al. 2007). In a recent 
study, it has been reported that in vivo oxidative stress production, accompanied by increasing oxidative stress markers after mustard gas exposure, was counteracted by melatonin administration (Pohanka et al. 2011). Melatonin was also able to ameliorate lung injury and oxidative stress induced by nitrogen mustard poisoning in rodents, suggesting it as a potential therapeutic target (Ucar et al. 2007). In an interesting review article, Korkmaz et al. (2008) proposed that the mechanism of delayed sulfur mustard toxicity may be due to epigenetic disruption that occurs in cells in which the genome has genetic and/or epigenetic mutations. As a multifunctional indole, melatonin could counteract delayed sulfur mustard toxicity, modulating the expression of mRNA levels for antioxidant enzymes under physiological conditions and during increased oxidative stress (Rodriguez et al. 2004).

Chlorine and phosgene, also known as choking agents, are the main lung-damaging agents. With water, chlorine produces hydrochloric $(\mathrm{HCl})$ and hypochlorous $(\mathrm{HOCl})$ acids and nascent oxygen. $\mathrm{HOCl}$ has a high capacity to inactivate enzymes involved in antioxidant defense system, inducing a disruption of redox homeostasis. The ability of one melatonin molecule to apparently interact with more than one $\mathrm{HOCl}$ molecule is consistent with observations made by Tan et al. (1998), who found that melatonin also neutralizes more than one hydroxyl radical. An interesting study, using the Chinese hamster B14 cell line, provided further evidence that $\mathrm{HOCl}$-induced toxicity was counteracted by melatonin. Melatonin co-administration significantly protected cells during $\mathrm{HOCl}$ exposure, diminishing its cytotoxic effects and reducing protein carbonyl generation (Zavodnik et al. 2004), and therefore, it may be an attractive therapeutic option to prevent inflammatory diseases where $\mathrm{HOCl}$ levels are known to be elevated.

There are no antidotes for lung-damaging poisoning agents, and medical treatment is based on ABC resuscitation, trying to prevent bronchospasm, hypoxia and pulmonary edema. The use of steroids has also been considered. Favoring the replacement of damaged airway epithelium may be able to avoid long-term effects.

Many antioxidants have been used to prevent oxidative stress prompted in phosgene-induced acute lung injury. Recently, Zhang et al. (2012) showed that melatonin afforded a protective effect in phosgene-induced lung injury, and they postulated that its protective mechanism may be associated with scavenging free radicals and inhibiting expression of iNOS and NF-кB.

Taking into account its versatility as direct free radical scavenger and indirect antioxidant, its anti-inflammatory activity, low toxicity and the absence of side effects, melatonin could be an excellent and suitable candidate molecule to prevent CWAs-induced tissue damage.

\section{References}

Collombet JM (2011) Nerve agent intoxication: recent neuropathophysiological findings and subsequent impact on medical management prospects. Toxicol Appl Pharmacol 255:229-241

Costa EJ, Lopes RH, Lamy-Freund MT (1995) Permeability of pure lipid bilayers to melatonin. J Pineal Res 19:123-126

Hardeland R, Cardinali DP, Srinivasan V, Spence DW, Brown GM, Pandi-Perumal SR (2011) Melatonin-a pleiotropic, orchestrating regulator molecule. Prog Neurobiol 93:350-384

Hengstler JG, Bolt HM (2007) Induction and control of oxidative stress. Arch Toxicol 81:823-824

Jafari M (2007) Dose- and time-dependent effects of sulfur mustard on antioxidant system in liver and brain of rat. Toxicology 231:30-39

Korkmaz A, Yaren H, Topal T, Oter S (2006) Molecular targets against mustard toxicity: implication of cell surface receptors, peroxynitrite production, and PARP activation. Arch Toxicol 80:662-670

Korkmaz A, Tan DX, Reiter RJ (2008) Acute and delayed sulfur mustard toxicity; novel mechanisms and future studies. Interdiscip Toxicol 1:22-26

Mauriz JL, Collado PS, Veneroso C, Reiter RJ, Gonzalez-Gallego J (2012) A review of the molecular aspects of melatonin's antiinflammatory actions: recent insights and new perspectives. J Pineal Res. doi:10.1111/j.1600-079X.2012.01014.x

Pohanka M, Sobotka J, Jilkova M, Stetina R (2011) Oxidative stress after sulfur mustard intoxication and its reduction by melatonin: efficacy of antioxidant therapy during serious intoxication. Drug Chem Toxicol 34:85-91

Reiter RJ, Tan DX, Manchester LC, Qi W (2001) Biochemical reactivity of melatonin with reactive oxygen and nitrogen species: a review of the evidence. Cell Biochem Biophys 34:237-256

Rodriguez C, Mayo JC, Sainz RM, Antolín I, Herrera F, Martín V, Reiter RJ (2004) Regulation of antioxidant enzymes: a significant role for melatonin. J Pineal Res 36:1-9

Sadir S, Deveci S, Korkmaz A, Oter S (2007) Alpha-tocopherol, betacarotene and melatonin administration protects cyclophosphamide-induced oxidative damage to bladder tissue in rats. Cell Biochem Funct 25:521-526

Seabra ML, Bignotto M, Pinto LR Jr, Tufik S (2000) Randomized, double-blind clinical trial, controlled with placebo, of the toxicology of chronic melatonin treatment. J Pineal Res 29: 193-200

Tan D, Chen L, Poeggeler B, Manchester L, Reiter R (1993) Melatonin: a potent, endogenous hydroxyl radical scavenger. Endocr J 1:57-60

Tan DX, Manchester LC, Reiter RJ, Plummer BF, Hardies LJ, Weintraub ST, Shepherd AM (1998) A novel melatonin metabolite, cyclic 3-hydroxymelatonin: a biomarker of in vivo hydroxyl radical generation. Biochem Biophys Res Commun 253: $614-620$

Ucar M, Korkmaz A, Reiter RJ, Yaren H, Öter S, Kurt B, Topal T (2007) Melatonin alleviates lung damage induced by the chemical warfare agent nitrogen mustard. Toxicol Lett 173:124-131

Zavodnik IB, Lapshina EA, Zavodnik LB, Łabieniec M, Bryszewska M, Reiter RJ (2004) Hypochlorous acid-induced oxidative stress in Chinese hamster B14 cells: viability, DNA and protein damage and the protective action of melatonin. Mutat Res 559: $39-48$

Zhang L, Shen J, Gan ZY, He DK, Zhong ZY (2012) [Protective effect of melatonin in rats with phosgene-induced lung injury]. Zhonghua lao dong wei sheng zhi ye bing za zhi = Zhonghua laodong weisheng zhiyebing zazhi $=$ Chinese journal of industrial hygiene and occupational diseases 30:834-838 